\title{
Fatores de Localização de Postos de Combustíveis em Fortaleza
}

\section{Location Factors of Gas Stations in Fortaleza}

João Adamor Dias Neves * Doutor em Administração e Negócios pela University of Stirling, Escócia. Professor na UECE, Fortaleza/CE, Brasil.

Átila Mendes Costa Mestre em Administração pela UECE. Professor na FCRS, Quixada/CE, Brasil.

*Endereço: Rua Tibúrcio Frota, 197, Bairro São João do Tauape, Fortaleza/CE, 60130-300. E-mail: joao_adamor@yahoo.com 


\title{
Resumo
}

O artigo investiga fatores locacionais nas decisões de postos de combustíveis [PCs]. Especificamente, (1) relacionam-se fatores de localização de Masano (2003) e Salvaneschi (1996); (2) descrevem-se atributos dos PCs de Fortaleza e (3) analisam-se fatores de microlocalização. Usa-se estudo exploratório, descritivo e censitário nos 255 PCs, via questionários e observação. Segundo os resultados, muitos PCs ficam em esquinas de ruas, ratificando a literatura específica. Em termos gerenciais, os resultados: (1) ajudam os donos de PCs nas decisões de localização; (2) permitem replicar o estudo e (3) subsidiam empreendedores e setor público a localizar melhor a atividade.

Palavras-chave: geomarketing; pequenas empresas; microlocalização.

\begin{abstract}
This paper investigates location factors to gas stations decision makers. Specifically it is aimed: (1) to relate location factors with geomarketing; (2) to describe aspects of Fortaleza's gas stations and (3) to analyze site location factors of gas stations. It is an exploratory, a descriptive and a census study via questionnaires and systematic observation to 255 gas stations. The findings show most of gas stations is located at street corners, thus confirming the literature review. In magerial terms, the findings: (1) help PCs owners to make decisions in locating business; (2) assist researchers to replicate the study and (3) help enterpreneuers and puclic sector to better choose local factors.
\end{abstract}

Key words: location; small firms; site location. 


\section{INTRODUÇÃO}

Conhecer, relacionar e examinar os fatores relevantes na determinação da localização de empresas é muito importante, pois somente através da interação e compreensão desses fatores é que se poderá avaliar o impacto e a utilização mais eficiente da localização empresarial do comércio varejista.

O número de empresas de varejo é muito grande e, a cada dia, novas empresas são criadas. Assim, o conhecimento dos fatores de localização é muito importante para o atual e futuro gestor varejista, por permitir-lhe decidir mais apropriadamente sobre o local de instalação de sua empresa, pois cada local pode ter impacto diferente no tipo de negócio.

Motivo: os fatores de localização não são sempre os mesmos nem no caso de um único tipo de comércio, porque há diferenças de uma região para outra em aspectos como técnicas de negócios disponíveis, condições de trabalho, tamanho e organização das firmas individuais, economia geral e ambiente social, dentre outros. Desse modo, essas variações poderão induzir a diferentes razões para uma boa localização varejista.

Por maiores que sejam as diferenças de localização, existe em cada caso uma combinação de influências que deve ser levada em conta para se proceder a uma boa escolha da localização varejista. Neste caso, a localização ideal implica um equilíbrio entre as influências, de modo que elas se entrelaçam harmonicamente, prestando cada uma sua devida contribuição, proporcionando as condições de trabalho mais satisfatórias ao bom desempenho da empresa.

Enfatize-se que poucos são os pequenos empreendedores que, ao procurar uma localização para nova loja, procedem a uma investigação acurada de todas as condições importantes que lhes propicie tomar uma decisão. A esse respeito, Buchanan e Estall (1976) dizem que muitas vezes há exemplos de decisões influenciadas por assuntos destituídos de qualquer relevância locacional. Por sua vez, Clarke, Horita e Mackaness (2000) corroboram essa idéia, dizendo que muitos tomadores de decisão de varejo são conhecidos por sua atitude indiferente, diante da avaliação de novos sítios para as suas lojas, e que, apesar do substancial avanço técnico realizado nos modelos de localização e sistemas de informação, esse procedimento descuidado continua a acontecer, fazendo com que freqüentemente as decisões locacionais de varejo sejam resultado de uma combinação de palpite, experiência e alguns poucos cálculos rudimentares. 
Segundo Fenker e Zoota (2001), como é comum haver decisões de localização de lojas baseadas no conhecimento do senso comum dos varejistas com relativa precisão, parece que a ciência e os avanços tecnológicos têm pouco impacto nas decisões da localização mais apropriada do negócio.

A escolha da localização de uma empresa é normalmente uma decisão racional, adotada após uma apreciação das vantagens relativas de diferentes localizações para as finalidades do negócio em particular, é uma das primeiras decisões do estabelecimento de uma empresa, ainda considerada a mais importante, porque é difícil voltar atrás, se a escolha for insatisfatória e, via de regra, pode-se considerar que a localização mais indicada é aquela que, sendo os outros fatores iguais, proporciona maior crescimento ou maior lucro.

Ressalte-se que, além de conhecerem os fatores de localização, é preciso que os empreendedores conheçam os fatores socioambientais, ou desenvolvendo uma consciência integrada de desenvolvimento sustentável, ou através de novos instrumentos de regulação e fiscalização de empresas por parte dos governos.

A literatura especializada comumente usa o termo localização em dois sentidos: um mais restrito, sítio (base topográfica), e um mais amplo, uma área ou localidade (Buchanan \& Estall, 1976). Assim, fator é aquilo que contribui para um resultado (Ferreira, 2004) e, neste caso, pode-se dizer que fator de localização é decisivo para a seleção de um sítio, de uma área ou localidade, apropriado para o funcionamento eficaz de uma empresa ou de um conjunto delas.

Com base nos argumentos anteriores, e considerando-se a escassez de estudos nessa área, o artigo investiga os fatores locacionais relevantes nas decisões dos donos de postos de combustível (pequenos negócios). Especificamente, pretendese: (1) relacionar os fatores de localização de acordo com os paradigmas de Masano (2003) e Salvaneschi (1996); (2) descrever os atributos dos postos de combustível [PCs] de Fortaleza e (3) identificar e analisar os fatores de microlocalização associados aos PCs de Fortaleza. Para isso, inicia-se com a abordagem dos diversos fatores de localização encontrados na literatura específica, considerando-se até mesmo alguns autores que tratam desse tema do ponto de vista da indústria, destacando-se os fatores de localização que melhor contemplem os postos de combustível, foco deste estudo (pequenas empresas varejistas). Depois, apresentam-se a metodologia e os resultados, seguindo-se as considerações finais e as referências 


\section{Fatores de localização: Visão Geral}

Os fatores de localização se inserem no âmbito do geomarketing, definido por Chasco (2003) como um sistema integrado por dados, programas informáticos de tratamento, métodos estatísticos e representações gráficas, destinados a produzir informações úteis aos tomadores de decisões econômicas, através de instrumentos ilustrativos que combinam a cartografia digital, gráficos e tabelas.

Porter (1999) diz que as diferenças nos valores nacionais, a cultura, as estruturas econômicas, as instituições e a história são fatores que contribuem para o êxito competitivo das empresas. Assim, em diferentes locais constatam-se disparidades marcantes nos padrões de competitividade e nenhum lugar específico (seja ele um bairro, cidade, região, ou país) é capaz de competir em todos os setores, nem mesmo na maioria desses setores. Em última instância, certos lugares obtêm êxito em determinados setores porque o ambiente doméstico é o mais apropriado.

Porter (1999) utilizou os quatro atributos considerados determinantes de competitividade nacional como fatores de localização, cujos detalhes são:

. Condições dos fatores - tratam da localização quanto aos fatores de produção, como mão-de-obra qualificada e infra-estrutura, necessários para competir num determinado setor.

. Condições da procura - tratam da natureza da procura no mercado interno para os produtos ou serviços do setor.

. Setores correlatos e de apoio - tratam da presença, ou a ausência, de setores fornecedores e outros correlatos que sejam competitivos.

. Estratégia, estrutura e rivalidade das empresas - dizem respeito às condições predominantes da localização, que determinam como as empresas são constituídas, organizadas e gerenciadas, assim como a natureza da rivalidade no mercado interno (Figura 1). 


\section{Figura 1: Modelo Diamante da Vantagem Competitiva Nacional}

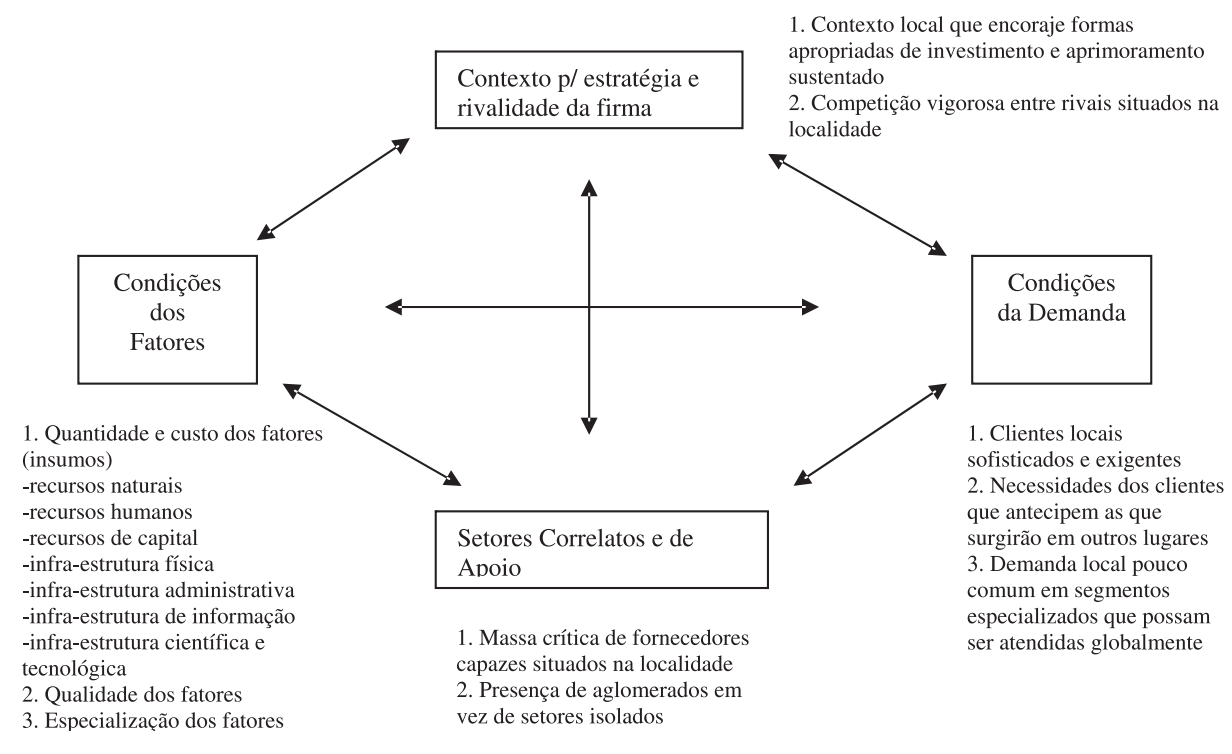

Fonte: Porter (1999, p. 224).

\section{Localização de Empresas e Urbanismo}

A dinâmica da estrutura urbana é aspecto importante para uma estratégia bemsucedida de localização, pois foi a partir do estudo de algumas das teorias de desenvolvimento urbano: teoria da uniformidade, das zonas concêntricas, do crescimento multinuclear, setorial e crescimento axial, Masano (2003) concluiu que o acesso é crítico para a atividade comercial. Isso, por si só, é suficiente para demonstrar que, nos estudos de geografia de mercado ou geomarketing, a análise da formação e da evolução urbana não pode ser negligenciada, pois o varejo é um demandador de espaço com características especiais de infra-estrutura. Assim, faz-se necessário que, nesses estudos, sejam analisados o zoneamento, o uso do solo, o sistema viário e as barreiras geográficas.

Para Dantas (2003), zoneamento significa a separação da cidade em zonas de usos distintos de habitação, comércio, lazer e circulação. Segundo Cullingworth (como citado em Souza, 2002, p. 250), a divisão do espaço sob jurisdição de um governo local em zonas será objeto de diferentes regulações quanto ao uso da terra, à altura e ao tamanho permitidos para as construções. Há vários tipos de zoneamento, variando, segundo Souza (2002), de acordo com sua finalidade e com sua índole, e cada um deles é um instrumento específico. Os tipos de zoneamento podem ser classificados em: (1) zoneamento funcionalista; (2) zoneamento de prioridade; (3) zoneamento não-funcionalista e (4) zoneamento de densidade. 
A técnica convencional de zoneamento gira em torno da separação de usos e densidades. O zoneamento de uso do solo pode chegar a ter grande grau de detalhes, com subcategorias, previsão de usos especiais etc., dependendo da escala e do nível de pormenor, incluindo objetos geográficos específicos (como hospitais, escolas e outros) podem vir a ser individualmente localizados e representados por meio de símbolos adequados.

As barreiras geográficas urbanas representam certa restrição à acessibilidade. Dentro dessa categoria podem ser citados: rios, lagos, mares, rodovias, pontes, grandes parques ou cemitérios (Masano, 2003). O mapeamento do sistema viário e das barreiras geográficas permite identificar compartimentos que se formam dentro de uma cidade, com implicações diretas na composição e distribuição do aparelho comercial.

O sistema viário forma a estrutura principal da cidade, constituindo, talvez, seu mais importante elemento. De acordo com a Associação Internacional de Administradores Municipais [AIAM] (1965), este sistema determina, em grande parte, a facilidade, a conveniência e a segurança com que o povo se locomove através da cidade; estabelece o tamanho das quadras; constitui um canal para luz e ar, bem como para instalações das redes aéreas e subterrâneas. Nenhum outro elemento da composição material da cidade é tão permanente quanto suas ruas. Uma vez aberta a rua, instalados os serviços públicos e beneficiados com construções os terrenos lindeiros, o fechamento, a relocalização ou alargamento da rua envolvem grandes dificuldades e despesas. De todas as funções do sistema de logradouros, entre as quais as de fornecer iluminação, ventilação e acesso, a da circulação de veículos é, indubitavelmente, a mais importante.

Segundo AIAM (1965), o congestionamento do tráfego não traz apenas inconvenientes e perigos; também causa prejuízos econômicos. Além dos prejuízos diretos causados pelo congestionamento do tráfego, atrasos e acidentes, há muitos outros indiretos, tais como perdas de negócios, aumento do custo de produção e desvalorização das propriedades imobiliárias.

De uma maneira geral, os sistemas viários apresentam hierarquias entre as suas vias. Um sistema viário pode ser dividido, por exemplo, em: rede primária com vias expressas e arteriais (grandes fluxos de média e longa distância); rede secundária, com vias coletoras (tráfego de média e curta distância, e de menor fluxo); e rede local (tráfego pequeno e baixa velocidade).

Para Masano (2003), a análise do sistema viário principal de uma cidade permite o entendimento preliminar da movimentação dos veículos e das pessoas dentro do tecido urbano. Assim, é possível avaliar as áreas mais servidas em termos viários, os principais entroncamentos, os tipos e volumes de fluxos, as 
configurações, isto é, os elementos que podem servir de subsídios para a escolha dos locais de negócios.

O mapeamento das áreas de concentração de atividades de comércio e serviços e dos grandes pólos geradores de tráfego contribuirá para o entendimento dos deslocamentos das pessoas e para identificação dos principais pontos de atração varejista da cidade.

Pólos Geradores de Tráfego [PGTs] são empreendimentos de grande porte que atraem ou produzem grande número de viagens, causando reflexos negativos na circulação viária em seu entorno imediato e, em certos casos, prejudicando a acessibilidade de toda a região, além de agravar as condições de segurança de veículos e pedestres (DENATRAN, 2001 como citado em Ary, 2002, p. 8). São exemplos de PGTs: shopping centers, hiper e supermercados, edifícios de escritórios, centros de convenções, escolas, faculdades, teatros, hospitais, conjuntos habitacionais, ginásios de esportes etc. (Ary, 2002; Masano, 2003).

De acordo com Ary (2002), os PGTs são classificados segundo o tipo de atividade a que se destinam, área construída do empreendimento, quantidade mínima de vagas de estacionamento necessárias ao atendimento da demanda, número de viagens geradas na hora de pico, localização em áreas críticas, entre outros.

Em conclusão, a localização dos empreendimentos é foco crescente de preocupações dos planejadores urbanos, principalmente no que diz respeito ao planejamento funcional do sistema viário. Dentre os efeitos provenientes destes pólos, pode-se destacar as alterações nos padrões de uso do solo em suas imediações, visto que em geral os PGTs atraem uma série de outras atividades complementares nessas áreas (Ulysséa \& Carvalho, 1992 como citado em Ary, 2002, p. 11).

\section{Fatores de Microlocalização}

Outro aspecto da dinâmica urbana, segundo Masano (2003), são os três fatoreschave na microlocalização de empresas de varejo: (1) acessibilidade, (2) os tipos de fluxo, e (3) o local, acrescentando que o grande dilema da escolha do local é que o grau de acessibilidade dos lugares varia enormemente em função dos sistemas e meios de transportes utilizados, e das barreiras geográficas existentes.

Para Masano (2003), a acessibilidade pode ser definida como a facilidade de se ter acesso aos demais pontos do espaço. A partir de maior ou menor grau de acessibilidade, pode-se verificar a existência de localizações ótimas para as diversas atividades varejistas. Ressalte-se que o varejista, quando se instala, 
procura maximizar o lucro do seu negócio; desse modo, está muito mais preocupado com o valor de uso do que com o valor de troca do imóvel.

Para avaliar preliminarmente a acessibilidade de um local, podem ser traçados num mapa raios a partir do ponto em estudo, que são denominados de isocotas. Esses raios são aproximações dos deslocamentos, por exemplo, 100m, 200m, e $300 \mathrm{~m}$ para uma padaria, ou $1 \mathrm{~km}, 2 \mathrm{~km}$ ou $3 \mathrm{~km}$ para um supermercado. Eles permitem visualizar as áreas que seriam abrangidas pela loja e possibilitam avaliações iniciais sobre o número de domicílios, empregos, renda e concorrência, mas a melhor maneira de avaliar a acessibilidade de um local é dada pela construção de isócronas (curvas de tempo-distância), cujos contornos podem ser feitos, por exemplo, em 5, 10, 15 minutos de automóvel, ou mesmo a pé. Quanto maior a área da isócrona, maior a acessibilidade comparativa do local (Masano, 2003).

As isócronas podem ser delineadas em relação ao ponto em estudo (isócrona de saída) ou ainda em relação aos locais a partir dos quais ele é atingido (isócrona de chegada). Em traçados urbanos, elas podem assumir formatos e áreas muito diferentes para o ponto em questão e para o consumidor, normalmente é mais repulsivo um maior tempo de ida que de volta.

Deve-se ressaltar que para uma boa localização não adianta haver apenas grande acessibilidade, também é de fundamental importância uma alta densidade de demanda. Isto é, tomando a farmácia como exemplo, onde os deslocamentos são pequenos, a sua localização numa área residencial verticalizada terá maior potencial do que se estiver numa área formada por residências unifamiliares.

Os tipos de fluxo variam, principalmente, em função da distribuição das atividades e moradias na ocupação do solo e do sistema de transportes de uma cidade. Normalmente, são classificados em tráfego do dia-a-dia, do trabalho, os de média e longa distância, e sazonal, cujo somatório para dado local determina o tráfego agregado (Salvaneschi, 1996).

O deslocamento decorrente das moradias (dia-a-dia) se circunscreve a uma área mais local, sendo determinado pelos deslocamentos para estabelecimentos de compras cotidianas, como padaria, açougue, farmácia, videolocadora ou prestadoras de serviços pessoais. A boa localização é aquela por onde passam mais pessoas, pois os consumidores vão lembrar-se mais daquela loja quando precisarem do produto (Masano, 2003).

O fluxo decorrente do trabalho determinado pela ligação residência-local de trabalho, é normalmente mais longo. Se a localização conseguir juntar os benefícios de atração das moradias e do fluxo de trabalho, isso se constituirá num diferencial 
extremamente positivo. É necessário lembrar, entretanto, que o tráfego das pessoas de casa para o trabalho ou vice-versa ocorre, normalmente em horários de pico durante o dia e quase inexiste nos finais de semana.

Entre os tráfegos de média distância estão aqueles para a aquisição de bens de compra comparada ou a ida a supermercados, restaurantes e shopping centers. Entre os de longa distância estão os deslocamentos referentes à aquisição de bens especializados, ida a teatros e eventos. É importante salientar que, no caso de um público sazonal, como o de turistas, os seus deslocamentos tendem a ser em maior número que aqueles dos moradores, num dado espaço de tempo, e muitos desses trajetos são de média e longa distância.

A topografia e o traçado viário têm implicações diretas na visibilidade de um imóvel e, conseqüentemente, no volume de negócios. Alguns tipos de configuração de logradouros são favoráveis à localização varejista, outros constituem situações desfavoráveis. É fácil, por exemplo, entender por que as localizações de esquina normalmente têm o valor de ponto superior às demais. Quanto mais pessoas passarem pelo local e maior a distância da qual enxergarem o negócio, mais tempo terão para decidir parar, e assim o fluxo à loja será maior.

De acordo com Salvaneschi (1996), entre as localizações consideradas pobres, por dificultarem ou inibirem o fluxo de consumidores, podem-se citar: (1) localizações em meio de quadra; (2) em eixo viário secundário; (3) em curva (pior quando interna); (4) em subida ou descida e (5) em rua sem saída. Além disso, o tipo de negócio poderá sofrer interferências do sentido da via, e no caso de um fast-food, a via centro-bairro é mais favorável, pois, em função do horário, a taxa de captura de clientes será maior no momento da volta para casa. Em determinadas atividades, a alteração de mão de direção da via pode até levar à inviabilidade do negócio, como no caso de um posto de gasolina.

Um dos fatores de sucesso da localização é o seu grau de exposição, normalmente favorecido, quando o negócio é implantado numa via arterial (Salvaneschi, 1996). Esse tipo de via se destaca pelos seguintes atributos: é mais larga e rápida do que as vias da vizinhança; possui maior volume de tráfego tanto durante o dia como à noite; é mais bem iluminada à noite; conecta várias partes da cidade; possui atividades comerciais bem estabelecidas nos dois lados; e, obviamente, tem o preço mais elevado por metro quadrado. Mesmo nessas vias devem ser evitadas as localizações entre as regiões de ligação, pois as pessoas que passam de automóvel nessas áreas estão preocupadas em sair o mais rápido possível de onde estão para chegar logo ao destino previsto. 


\section{Fatores de Localização}

Para Lira (2001), as diferenças entre regiões e entre comunidades de uma mesma grande cidade, fruto de condições impostas pelo subdesenvolvimento econômico (principalmente a pobreza), constituem um fator de perda de produtividade e de produção para as empresas. Assim, entende-se que um nível médio ou elevado de renda, assim como uma equilibrada distribuição dela, funcionem como fator de atração para pequenos empreendedores, influenciando na localização de suas empresas.

Conforme Aranha e Bussab (2000), a chave para a alocação eficiente de recursos de marketing é o conhecimento do potencial de cada segmento geográfico em relação aos demais. O potencial de mercado geralmente é entendido como uma função procura, em que as variáveis explicativas mais freqüentemente encontradas na literatura mercadológica e econômica são: tempo; localização onde a demanda é quantificada; renda da população ali residente; riqueza da população; suas preferências; estrutura socioeconômica do mercado; e esforço mercadológico total das empresas ofertantes dos produtos.

A governabilidade é outro fator da revalorização dos territórios, pois em contexto aberto e competitivo, a estabilidade econômica dos países da região e o êxito competitivo dos sistemas produtivos dependem, sobretudo, da capacidade de ativar crescimento, gerando empresas, competências e inovações através das forças e das instituições locais e suas relações (Lira, 2001, p. 11).

Meyer-Stamer (2001), tratando do tema "estratégias de desenvolvimento local e regional", fala da necessidade de uma política de localização ativa e criativa, distante da promoção econômica convencional, e propõem um modelo de quatro triângulos, onde um deles lida especificamente com os fatores de localização de empresas. O triângulo é dividido em fatores objetivos e subjetivos: esses últimos são subdivididos em fatores subjetivos empresariais e fatores subjetivos pessoais.

Os fatores objetivos de localização mais importantes, segundo Meyer-Stamer são: posição geográfica em relação aos mercados de compra e venda; ligação à rede de transportes (rodovias, ferrovias, portos, aeroportos); oferta de mão-deobra (qualificada e adequada, nível salarial); disponibilidade de terrenos; custos com energia e meio ambiente; encargos municipais; e vantagens financeiras oferecidas pela cidade ou estado (incentivos fiscais, subvenções etc.).

Por sua vez, os fatores subjetivos de localização de empresas mais importantes são: ambiente econômico da cidade e da região correspondente; imagem da cidade / região; contatos com empresas do mesmo setor; universidades, instituições de 
pesquisa e tecnologia; perfil inovador da região; e desempenho de associações comerciais e industriais.

Os fatores subjetivos pessoais mais importantes citados por Meyer-Stamer são: a qualidade residencial e de seu entorno; a qualidade do meio ambiente; a qualidade das escolas e de outras instituições de formação; a qualidade da infra-estrutura e a qualidade e diversidade do lazer.

Porter (1999) argumenta que a solução dos problemas sociais dos bairros centrais decadentes das cidades norte-americanas não é a criação de programas sociais de atendimento das necessidades individuais, ou programas de desenvolvimento econômico de abordagens isoladas e fragmentadas, mas a criação de condições para a proliferação e crescimento para as empresas situadas nestes bairros, desta forma, dando oportunidades de emprego nas adjacências para os residentes locais.

Chau e Pretorius (2002), focando lojas de varejo, dizem que antigas áreas urbanas com restrições de reformas e com crescimento sem um planejamento adequado têm seu desenvolvimento de forma tal que as excelentes localizações são ocupadas primeiro, seguidas então pela ocupação de outras localizações menos estratégicas, que se dão de acordo com a expansão urbana. A reputação das excelentes localizações se desenvolve com o tempo, e dessa maneira, a idade da propriedade também funciona como fator de localização.

Em síntese, pode-se verificar que são muitos os fatores de localização e que eles variam: (1) quanto a sua natureza, seja ela econômica, social, ambiental, cultural etc.; (2) quanto ao objeto de estudo, no caso, postos de combustível; e (3) quanto à escala de aproximação da análise pretendida, podendo variar desde a posição do estabelecimento na quadra (microlocalização), até a análise do melhor país ou bloco econômico para localizar uma empresa (análise global). A escala de análise utilizada neste estudo e seus respectivos fatores de localização é a da microlocalização.

\section{Metodologia}

Trata-se de investigação exploratória em área em que há pouco conhecimento acumulado e sistematizado. Por sua natureza de sondagem, não comporta hipóteses que, todavia, poderão surgir durante ou no final da pesquisa. Assim, utiliza-se estudo exploratório bibliográfico e empírico, seguido de estudo descritivo quantitativo, com pesquisa de campo via observação sistemática. 
O estudo é exploratório porque, embora haja grande número de pequenas empresas na cidade de Fortaleza, não se verificaram estudos sobre a localização de postos de combustível, objeto deste estudo. Por outro lado, trata-se também de estudo descritivo porque descreve aspectos qualitativos dos postos de combustíveis, identifica e analisa fatores de microlocalização desses postos de combustíveis.

O estudo exploratório bibliográfico incluiu pesquisas em livros, revistas, jornais, redes eletrônicas, dissertações e teses sobre pequenas empresas, fatores de localização de indústrias, comércio e serviços e estratégias de localização.

O estudo exploratório empírico foi feito através de uma pesquisa de campo, utilizando-se observação sistemática junto aos PCs de Fortaleza, a fim de verificar detalhes dos fatores de microlocalização e caracterizar o objeto de pesquisa.

A observação sistemática ou observação estruturada, planejada ou controlada usa instrumentos para a coleta dos dados ou fenômenos observados. Realiza-se em condições controladas, a fim de responder a objetivos preestabelecidos, mas as normas não devem ser padronizadas nem rígidas demais, porque tanto as situações como os objetos e objetivos da pesquisa podem ser muito diferentes, de modo que deve ser planejada com cuidado e sistematizada (Neves, 2004).

Trata-se de estudo censitário, abrangendo todo o universo dos postos de combustíveis da cidade de Fortaleza e incluiu todos os PCs que se encontram em funcionamento na cidade de Fortaleza durante o segundo semestre do ano de 2006, cujo número foi estimado em 263 PCs, de acordo com a Junta Comercial do Estado do Ceará [JUCEC]; porém constatou-se em campo o funcionamento de apenas 255 PCs. Dentre os 255 PCs estão incluídos 4 novos PCs que se encontram completamente construídos, mas que ainda não foram inaugurados. Além disso, verificaram-se três PCs antigos fechados ou abandonados, razão por que eles não foram incluídos na relação dos 255.

Como se trata de estudo censitário e apesar dos custos operacionais da observação sistemática, realizou-se um trabalho completo, com todos os PCs do município de Fortaleza e, como tal, não se justificou o uso de amostra no estudo.

A unidade amostral, base do processo de seleção, foi o posto de combustível. A unidade de listagem foi a lista dos nomes e endereços das empresas pesquisadas adquirida na JUCEC, o que de certa forma legitima a totalidade das empresas pesquisadas, já que todos os postos de combustíveis são obrigados a se cadastrarem neste órgão, sob pena de serem tidos como empresas ilegais. Finalmente, a unidade de observação, que representa exatamente o que está sendo pesquisado, foram os sítios onde funcionam e estão localizados os PCs da cidade de Fortaleza. 
O instrumento de coleta de dados foi um questionário estruturado, com duas perguntas abertas, três perguntas de múltipla escolha e nove perguntas dicotômicas, todas relacionadas aos fatores de microlocalização e características dos PCs.

Para a construção do questionário seguiram-se as recomendações de Nachmias e Nachmias (1996); Mattar (2001); Vergara (1998). As perguntas procuram identificar empiricamente os fatores de localização descritos por Masano (2003); Salvaneschi (1996) e verificar se as decisões de microlocalização dos empreendedores de PCs de Fortaleza condizem com a teoria sobre o tema. Os dados coletados serão inseridos, organizados e analisados em planilhas eletrônicas do software Microsoft Excel 2005.

\section{RESULTADOS}

A análise considerou vários fatores de microlocalização descritos por Masano (2003); Salvaneschi (1996), como classificação das vias, inclinação do terreno, situação na quadra e forma da via, e os aspectos qualitativos dos PCs.

De acordo com Salvaneschi (1996) um dos fatores de sucesso da localização é o grau de exposição, normalmente favorecido, quando o negócio é implantado em via arterial. Segundo os resultados, a maioria dos PCs está localizada em vias arteriais, representando $64 \%$ do total, indicando uma localização de grande volume de tráfego, o que favorece em muito o desempenho do negócio.

Com base nos resultados, verifica-se que $88 \%$ dos PCs estão localizados em terreno plano, facilitando sobremaneira a visualização e fácil acesso ao estabelecimento por parte do motorista (Masano, 2003; Salvaneschi, 1996), ressaltando-se que a topografia da cidade, por ser plana, favorece bastante a localização.

A localização de PC na esquina de logradouro público mereceu a preferência da maioria dos proprietários (87\%), indicando conhecimento do senso comum na aplicação de técnicas de geomarketing, pois a esquina tem o dobro do volume de tráfego de veículos e, dessa forma proporciona vantagens de localização (Salvaneschi, 1996).

Em relação à forma e ao tipo de via, os dados da pesquisa indicam que a quase totalidade dos PCs (93\%) prefere a forma de via reta, porque, de acordo com Masano (2003), isso facilita a visualização e acesso por parte dos veículos. Por sua vez, o tipo de via predominante na localização dos PCs é a de mão-dupla, ressaltando-se que não existem PCs localizados em vias sem saída na cidade.

Em relação ao uso mais racional do espaço dos PCs, a observação sistemática 
mostrou que mais da metade das pessoas condutoras de veículos utiliza loja de conveniência, provavelmente para rentabilizar o espaço com outra atividade econômica de interesse de quem conduz o veículo.

Os serviços complementares mais utilizados pelos PCs são troca de óleo (84\%) e lavagem de carro (73\%), serviços estes capazes de alavancar vendas e fidelizar os clientes.

Com relação aos combustíveis diferentes de gasolina, comuns em todos os PCs da cidade, o diesel é vendido na quase totalidade deles (95\%), seguido de perto pelo álcool (94\%) e por pequena percentagem de gás natural $(16 \%)$.

Em relação às bandeiras (marcas) dos PCs, predomina a bandeira da Petrobrás (32\%), seguindo-se os postos Sobral \& Palácio (15\%), Texaco (12\%), Esso (10\%).

Em conclusão, na análise da microlocalização feita, pode-se dizer que a maioria dos PCs de Fortaleza está em consonância com os fatores de situação levantados na literatura e discutidos por Masano (2003); Salvaneschi (1996).

\section{Considerações Finais}

Do ponto de vista acadêmico, este trabalho examina algumas questões importantes no campo da aplicação do geomarketing, entre elas: (1) o foco nos fatores de localização de postos de combustível; (2) o exame dos fatores e das características de localização de empreendimentos varejistas; e (3) a aplicabilidade destes fatores em postos de combustíveis.

O estudo desenvolvido teve como eixo teórico os fatores de localização empresarial e possibilitou a construção de uma compreensão atualizada das práticas de localização na realidade dos pequenos negócios, no caso presente, postos de combustível. Para tanto tomou-se como campo de pesquisa um estudo em duzentos e cinqüenta e cinco postos de combustíveis na cidade de Fortaleza.

O objetivo (1) relacionar os fatores de localização discutidos na literatura foi atingido, via enumeração dos mais diversos fatores de localização, suas diferentes escalas de aproximação do objeto, incluindo diferentes setores empresariais.

Sobre o objetivo (2) descrever os atributos qualitativos dos PCs de Fortaleza, os resultados do estudo permitem dizer que ele foi atingido, uma vez que, durante a pesquisa de campo se levantaram junto aos PCs informações relativas à variedade de produtos ofertados (gasolina, álcool, diesel e gás natural), à 
disponibilidade de serviços complementares (loja de conveniência, troca de óleo e lavagem de carro) e às marcas (bandeiras) dos PCs da cidade.

O objetivo (3) identificar e analisar os fatores de microlocalização, associados aos PCs de Fortaleza, foi atingido, porquanto, a partir dos resultados, foi possível realizar uma análise comparativa entre os princípios teóricos da microlocalização empresarial e o pragmatismo das tomadas de decisões locacionais dos donos de postos de combustível, os quais não contaram, segundo eles, com o apoio técnico das bandeiras das marcas comercializadas nos respectivos PCs.

Na literatura encontram-se duas correntes contrárias de pensamento em relação à atitude locacional dos pequenos empreendedores varejistas: (1) os teóricos que pensam que os pequenos empreendedores varejistas, muitas vezes, tomam decisões influenciadas por assuntos destituídos de qualquer relevância locacional e que eles deveriam fazer uso dos modelos de localização e sistemas de informação propiciados pelos avanços tecnológicos (Buchanan \& Estall, 1976; Clarke et al., 2000); e (2) os teóricos que pensam que os processos empíricos de tomada de decisões de localização desses pequenos empreendedores devem ser mais bem estudados e que os sistemas de informação atuais, muitas vezes, mimetizam esses procedimentos pragmáticos (Fenker \& Zoota, 2001).

Considerando os resultados obtidos, a partir dos dados coletados em campo e as análises realizadas com os fatores de localização discutidos por Masano (2003); Salvaneschi (1996), parece haver uma associação entre os princípios teóricos levantados na pesquisa bibliográfica e a localização dos PCs envolvidos na análise. Dessa forma, é possível dizer que os pequenos empreendedores têm locado suas empresas em consonância com os princípios teóricos da localização empresarial, mesmo não fazendo uso de métodos científicos, modelos analíticos ou ferramentas sofisticadas, principalmente porque não contaram com o apoio técnico das distribuidoras das bandeiras. Assim e de acordo com Fenker e Zoota (2001), o processo pragmático de localização de empresas utilizado por pequenos empreendedores é apoiado principalmente na experiência própria e no conhecimento do senso comum.

Em relação à prioridade dada pelos donos de PCs aos fatores de localização pôde-se observar em entrevistas informais que o volume de tráfego da via e número de concorrentes na mesma via aparecem como os fatores mais relevantes; porém esta análise qualitativa está ligada a estudos de valor e tomadas de decisão, e devem ser objeto de estudos posteriores.

Os resultados sugerem que os donos de PCs não realizam nenhum estudo formal de localização, por ocasião da decisão de localizar seu PC; porém seria necessário realizar outra pesquisa para confirmar tal hipótese. Dessa forma, recomenda-se a realização de pesquisa qualitativa com entrevistas direcionadas aos proprietários 
dos PCs, a fim de verificar com mais precisão os procedimentos e as estratégias de localização adotados pelos donos de postos de combustíveis.

Por fim, acrescenta-se que o estudo ora realizado não esgota o assunto; porém acredita-se que o seu resultado possa incrementar o conhecimento de estratégias de localização aplicadas a postos de combustível (pequeno varejo). Assim, em termos gerenciais, os resultados do estudo ora realizado podem ser úteis: (1) aos proprietários de postos de combustível, por permitir subsidiar atuais e futuras decisões de localização de pequenos negócios; (2) a outros pesquisadores, para replicar o estudo feito; e (3) aos empreendedores em geral, e ao próprio setor público, para ajudá-los a escolher melhor o local do empreendimento ou da atividade com base em informações técnicas.

\section{Artigo recebido em 16.10.2006. Aprovado em 23.11.2007.}

\section{Referências Bibliográficas}

Aranha, F., \&

Bussab, W. O. de (2000).

A geographically informed model for market potential. Proceedings of the Bussiness Association of Latin American Studies, Caracas, Venezuela. Recuperado em 10 julho, 2005, de http://www.fgvsp.br/ a c a d e m i co/profes s ores/ Francisco_Aranha/GeoInformed.PDF

Ary, M. B. (2002).

Análise da demanda de viagens atraídas por shopping centers em Fortaleza. Dissertação de mestrado não-publicada. Universidade Federal do Ceará, Fortaleza, CE, Brasil. Recuperado em 12 junho, 2005, de http://metro.det.ufc.br/petran/teses/ tese13.pdf

Associação Internacional de Administradores Municipais. (1965).

Planejamento urbano. Rio de Janeiro: FGV.
Ferreira, A. B. H. de (2004).

Dicionário da língua portuguesa (6a ed.). Curitiba: Positivo.

Buchanan, R. O., \&

Estall, R. C. (1976).

Atividade industrial e geografia econômica (2a ed.). Rio de Janeiro: Zahar.

Chasco, C. (2003).

El geomarketing y la distribución comercial. Investigación y Maketing, (79), 6-13.

Chau, K. W., \&

Pretorius, F. (2002).

Retailer's location preferences: the influence of time, micro-spacial and property characteristics in a highdensity urban area [Discussion paper series]. Faculty of Architeture, Hong Kong: University of Hong Kong. 
Clarke, I.,

Horita, M., \&

Mackaness, W. (2000).

The spatial knowledge of retail decision makers: capturing and interpreting group insight using a composite cognitive map. The International Review of Retail, Distribution and Consumer Research, 10(3), 265-285.

Dantas, M. G. A. de (2003).

Planejamento urbano e zoning. João Pessoa: Editora universitária UFPB.

Fenker, R., \&

Zoota, J. (2001).

Intuitive retail modelling: does science have anything to offer? Journal of Corporate Real Estate, 3(3), 248-259. Recuperado em 4 fevereiro, 2005, de http:// www.ingentaconnect.com/content/ hsp/cre/2001/00000003/00000003

Lira, P. F. M. (2001).

El ordenamiento territorial como opción de políticas urbanas y regionales em América Latina y el Caribe. Serie medio ambiente y desarrollo $\left(\mathrm{n}^{\circ} 45\right)$. Santiago de Chile: CEPAL. Recuperado em 8 dezembro, 2004, de http://www.cepal.cl/cgi-bin/ getProd.asp?xml=/publicaciones/xml/ 8/9698/P9698.xml\&xsl=/dmaah/tpl/ p9f.xsl\&base=/tpl/top-bottom.xslt

Masano, T. F. (2003).

Geografia de mercado. In S. R. Dias (Coord.). Gestão de marketing (pp. 167-213). São Paulo: Saraiva.

Mattar, F. N. (2001).

Pesquisa de marketing (3a ed., edição compacta). São Paulo: Atlas.
Meyer-Stamer, J. (2001).

Estratégias de desenvolvimento local e regional: clusters, política de localização e competitividade sistêmica [Working Paper $\mathrm{N}^{\circ}$ 28]. Instituto Latinoamericano para o Desenvolvimento Ecológico e Sustentável (ILDES), São Paulo, SP. Recuperado em 23 agosto, 2004, de h t t p : / / w w w. f e s . org.br/ default.asp?paginaId $=142$

Nachmias, C. F., \&

Nachmias, D. (1996).

Research methods in the social sciences (5a ed.). New York: St. Martin's Press.

Neves, J. A. (2004).

Metodologia de pesquisa. Fortaleza: Universidade Estadual do Ceará.

Porter, M. E. (1999).

Competição: estratégias competitivas essenciais (9a ed.). Rio de Janeiro: Campus.

Salvaneschi, L. (1996).

Location, location, location: how to select the best site for your business. Grants Pass, Estados Unidos da América: Oasis Press.

Souza, M. L. de (2002).

Mudar a cidade: uma introdução crítica ao planejamento e à gestão urbanos. Rio de Janeiro: Bertrand Brasil.

Vergara, S. C. (1998).

Projetos e relatórios de pesquisa em administração (2a ed.). São Paulo: Atlas. 